\title{
RNAi gene therapy of SiHa cells via targeting human TERT induces growth inhibition and enhances radiosensitivity
}

\author{
WENXUAN ZHANG and LINA XING
}

\begin{abstract}
Department of Radiation Oncology, The 2nd Affiliated Hospital of Harbin Medical University, Harbin 150086, P.R. China
\end{abstract}
Received June 4, 2013; Accepted July 16, 2013

DOI: 10.3892/ijo.2013.2051

\begin{abstract}
Telomerase activity (TA) is reactivated in more than $90 \%$ of all human malignant tumors and normal somatic cells that lack TA. Thus, human TERT (hTERT) is a promising target in malignant tumor treatment. RNA interference is a powerful tool for gene silencing. In this study, we constructed siRNA\#1-4 to knock down hTERT. All siRNAs were able to downregulate hTERT differently and we chose siRNA\#3 (most effectively) in the following experiments. We studied the effects on cell proliferation, cell cycle, cell apoptosis and radiosensitivity using SiHa cells. Our results showed that siRNA\#3 was able to silence hTERT gene effectively. The silencing of hTERT could induce immediate growth arrest, enhance the $S$ phase in cell cycle study and lead to early apoptosis in human cervical cancer cells ( $\mathrm{SiHa}$ ). In clonogenic assays, we used multitarget-single hit and linear-quadratic models to assess the radiosensitivity after knockdown of hTERT. All results of parameters $\left(D_{0}, D_{q}, \alpha, \beta\right)$ indicated that downregulation of hTERT enhanced radiosensitivity in SiHa cells.
\end{abstract}

\section{Introduction}

Telomeres are important DNA-protein structures that cap the ends of chromosomes with TTAGGG repeats (1). This is essential to maintain genomic integrity and stability by protecting chromosome ends from DNA damage response $(2,3)$. Telomerase activation is responsible for maintaining the length of telomere and is regarded as a marker for human malignancies. Telomerase is a ribonucleoprotein complex including two subunits: the human telomerase RNA (hTR) and the human telomerase reverse transcriptase (hTERT). hTERT is the protein subunit and catalyze the process of the synthesis of the telomeric DNA $(4,5)$. It permits cancer cells to compensate the progressive loss of telomere during cell division and thus plays a critical role in cell immortality. In most normal

Correspondence to: Professor Lina Xing, Department of Radiation Oncology, The 2nd Affiliated Hospital of Harbin Medical University, 148 Baojian Road, Nangang District, Harbin 150086, P.R. China E-mail: xinglina1960@sina.cn

Key words: human TERT, SiHa cells, radiosensitivity, apoptosis human somatic cells, telomerase activity is at low level or undetectable. However, the increased telomerase activity (TA) is found in $90 \%$ human cancer cells $(6,7)$. Therefore, inhibition of hTERT could be a good antitumor strategy, which was successfully used to reduce cancer cell growth $(8,9)$.

Human cervical cancer is a prevalent cancer worldwide. The treatment outcome for human cervical cancer is poor, despite improved understanding of its pathogenesis. The main reason is recurrence after radiation that induces repopulation in cancer cells. SiHa is a squamous cell carcinoma cell line established from fragments of a primary tissue sample obtained after surgery from a Japanese patient.

Ionizing radiation (IR) is an important local therapeutic way that induces DNA damage and double-stranded breaks and is used in at least $50 \%$ of all cancer patients (10). Radiationinduced cell death is usually attributed to DNA damage, which induces cell apoptosis. A major factor in the failure of radiotherapy is cellular radioresistance. Telomerase can heal chromosomes or chromatid breaks produced by this damage. Thus, telomerase is a novel hallmark of cellular radiosensitivity and it is possible to downregulate telomerase to enhance radiosensitivity in human cancer cells.

\section{Materials and methods}

Cell culture. Human cervical cancer SiHa cells (Research Center of The 2nd Affiliated Hospital of Harbin Medical University) were maintained in Dulbecco's minimum essential medium (DMEM, Invitrogen) supplemented with $10 \%$ fetal calf serum (Gibco), penicillin $(100 \mathrm{U} / \mathrm{ml})$ and streptomycin $(100 \mu \mathrm{g} / \mathrm{ml})$ and incubated at $37^{\circ} \mathrm{C}$ in a humid environment containing $95 \%$ air $/ 5 \% \mathrm{CO}_{2}$.

Construction of hTERT-siRNAs and transfection. hTERTsiRNA (1-4) and siRNA-NC (negative control) were constructed by Genepharm (Table I). The presence of siRNA sequences were confirmed by DNA sequencing. Transfection was performed when the cells were $80-90 \%$ confluent using $5 \mu 1$ SiRNA-Mate (Genepharm, Shanghai, China) and 100 pmol SiRNA (Genepharm), according to the manufacturer's recommendations. The SiRNA-Mate-SiRNA complex was allowed to incubate with the cells for 4-6 h before removal and incubating with fresh culture medium supplemented with antibiotics. Transfection efficiency was calculated $6 \mathrm{~h}$ after the transfection by the percentage of green fluorescent 
Table I. Sequences of siRNAs used.

\begin{tabular}{llc}
\hline siRNA & \multicolumn{1}{c}{ Sequences of siRNA } & Target site on hTERT \\
\hline 1 & $\mathrm{~S}\left(5^{\prime} \rightarrow 3^{\prime}\right):$ CCGAAGAAGCCACCUCUUUTT & hTERT-homo-984 \\
& $\mathrm{A}\left(5^{\prime} \rightarrow 3^{\prime}\right):$ AAAGAGGUGGCUUCUUCGGTT & \\
& $\mathrm{S}\left(5^{\prime} \rightarrow 3^{\prime}\right):$ GCUCGUGGAGACCAUCUUUTT & hTERT-homo-1135 \\
& $\mathrm{A}\left(5^{\prime} \rightarrow 3^{\prime}\right):$ AAAGAUGGUCUCCACGAGCTT & \\
& $\mathrm{S}\left(5^{\prime} \rightarrow 3^{\prime}\right):$ GGAAGAGUGUCUGGAGCAATT & hTERT-homo-1788 \\
& $\mathrm{A}\left(5^{\prime} \rightarrow 3^{\prime}\right):$ UUGCUCCAGACACUCUUCCTT & \\
& $\mathrm{S}\left(5^{\prime} \rightarrow 3^{\prime}\right):$ GCACCAACAUCUACAAGAUTT & hTERT-homo-3049 \\
& $\mathrm{A}\left(5^{\prime} \rightarrow 3^{\prime}\right):$ AUCUUGUAGAUGUUGGUGCTT & \\
$\mathrm{NC}$ & $\mathrm{S}\left(5^{\prime} \rightarrow 3^{\prime}\right):$ UUCUCCGAACGUGUCACGUTT & \\
& $\mathrm{A}\left(5^{\prime} \rightarrow 3^{\prime}\right):$ ACGUGACACGUUCGGAGAATT & \\
\hline
\end{tabular}

S, sense. A, antisense.

protein (GFP) expressing cells with an LSM 510 META (Carl Zeiss).

Real-time PCR analysis. Total RNA was extracted from $\mathrm{SiHa}$ cells with TRIzol reagent (Invitrogen, USA) following the protocol instructed by the manufacturer and quantified.cDNA and real-time PCR reaction system was prepared with realtime PCR Universal reagent (Genepharm) according to standard protocols. Primer sets and probes for hTERT were: forward, 5'-GGCGACATGGAGAACAAGC-3'; reverse, 5'-CAAGAAATCATCCACCAAACG-3'; the predicted band was 75 bp. For HGAPDH: forward, 5'-CATGAGAAGTAT GACAACAGCCT-3'; reverse, 5'-AGTCCTTCCACGATACC AAAGT-3' (113 bp). The cycling program was $95^{\circ} \mathrm{C}$ for $3 \mathrm{~min}$, $95^{\circ} \mathrm{C}$ for $30 \mathrm{sec}, 62^{\circ} \mathrm{C}$ for $40 \mathrm{sec}$ ( 40 cycles). The relative expression level of RNA was computed using the $2^{-\Delta \Delta \mathrm{Ct}}$ analysis method and HGAPDH was used as an internal reference. Each experiment was repeated three times.

Western blot analysis. Cells were harvested from the plates on ice. The proteins ( $20 \mu \mathrm{g} /$ lane) were extracted with M-PER Mammalian Protein Extraction Reagent (Thermo) and separated on an $8 \%$ SDS-polyacrylamide gel. The proteins were transferred to PVDF membrane (Millipore) and then blocked with $5 \%$ milk in Tris-buffered saline containing $0.05 \%(\mathrm{v} / \mathrm{v})$ Tween-20 for $1 \mathrm{~h}$ at room temperature. The membranes were incubated overnight with primary antibodies anti-hTERT (Epipomics 1:1,000) and $\beta$-actin (Sigma 1:5,000) and then washed there times and incubated with secondary antibodies (HRP-conjugated goat anti-rabbit 1:8,000) for $2 \mathrm{~h}$. The protein bands were visualized using SuperSignal West Pico Chemiluminent Substrates (Thermo). The analysis of band intensity was performed with Gel-Pro analyzer. Each experiment was repeated three times.

Cell proliferation. Cell growth was calculated with CCK-8 assay (Dojindo Kumanmoto). Cells $(5,000)$ were plated in 96-well and transfection with siRNAs. Three wells were selected every 24-168 h. CCK-8 (10 $\mu \mathrm{l})$ was added to each well and incubated for $2 \mathrm{~h}$. The absorbance of samples was measured at $450 \mathrm{~nm}$. Each experiment was repeated three times.

Flow cytometry analysis. Analysis of samples was performed with Cytomics ${ }^{\mathrm{TM}}$ FC500 (Beckman). Cells were harvested with trypsinization and fixed with $-20^{\circ} \mathrm{C}, 70 \%$ ethanol and stored an $4^{\circ} \mathrm{C}$ overnight. RNaseA $(150 \mu \mathrm{l})$ and propidium iodide (PI) $(100 \mu \mathrm{l})$ were added in the resuspended fixed cells and the cell cycle was analyzed. Apoptosis was assessed with Annexin V/PI (Mbchem M3031). Cells were washed and resuspended in $400 \mu \mathrm{l}$ binding buffer (Mbchem M3036) and $5 \mu \mathrm{l}$ Annexin V-FITC, followed by incubation for $5 \mathrm{~min}$ at room temperature in the dark (11). After that, flow cytometry was used to detect cell apoptotic rate. Each experiment was repeated three times.

Clonogenic assay and irradiation. The cells were planted in 60 -mm dishes for $\sim 12 \mathrm{~h}$ in complete medium until attached, then cells were radiated with different doses of 6-MV X-ray $(0,2,4,6$ and $8 \mathrm{~Gy})$ at room temperature. X-ray was generated by a $23 \mathrm{EX}$ accelerator (Elekta) and the dose efficiency was $400 \mathrm{cGy} / \mathrm{min}$. The medium was changed with a fresh one $24 \mathrm{~h}$ later and incubated at $37^{\circ} \mathrm{C}$ in $95 \%$ air $/ 5 \% \mathrm{CO}_{2}$ for 14 days. The cells were stained with Giemsa and counted to determine the survival fraction of each group. Colonies with $>50$ cells were counted. Each experiment was repeated three times. Standard radiation survival curve was constructed and the parameters $\mathrm{D}_{0}, \mathrm{D}_{\mathrm{q}}$ as well as $\alpha$ and $\beta$ were calculated with the multitargetsingle hit model and linear-quadratic model. $\mathrm{D}_{0}$ means the dose required to reduce the fraction of surviving cells to $37 \%$ of its previous value. $\mathrm{D}_{\mathrm{q}}$ means the repair capacity of the cells after radiation.

Statistical analysis. All numerical experimental data were expressed as means \pm SD and statistical analysis of results were performed using ANOVA. $D_{0}, D_{q}, \alpha$ and $\beta$ were calcu- 


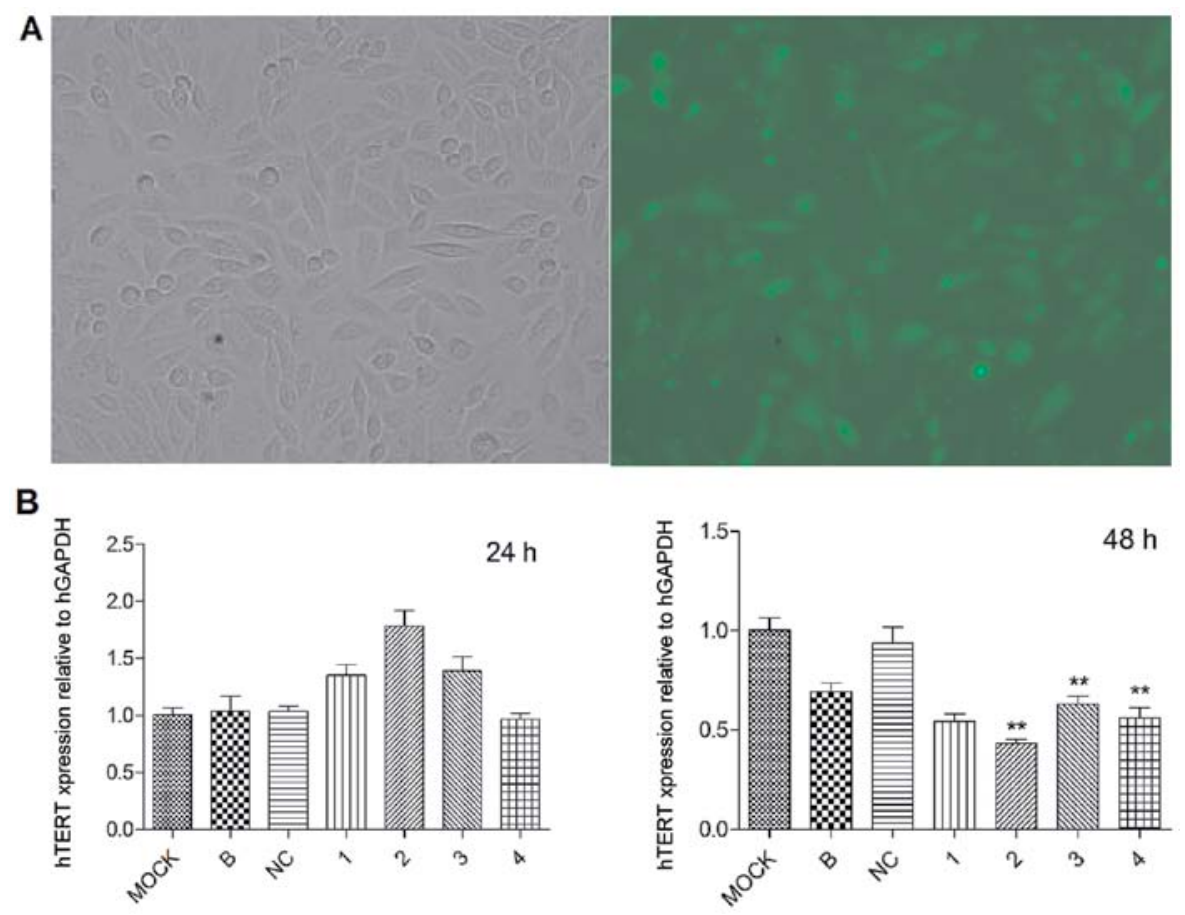

Figure 1. (A) siRNA transfection efficiency. (B) hTERT mRNA expression level by real-time RT-PCR at 24 and $48 \mathrm{~h}$ after transfection. ${ }^{*} \mathrm{P}<0.05 ;{ }^{* *} \mathrm{P}<0.01$ respectively, compared with control of mock. Data shown are representative of three independent experiments. Mock, siRNA-mate transfection only. B, Blank control. NC, negative control. 1, siRNA\#1. 2, siRNA\#2.3, siRNA\#3. 4, siRNA\#4.

A

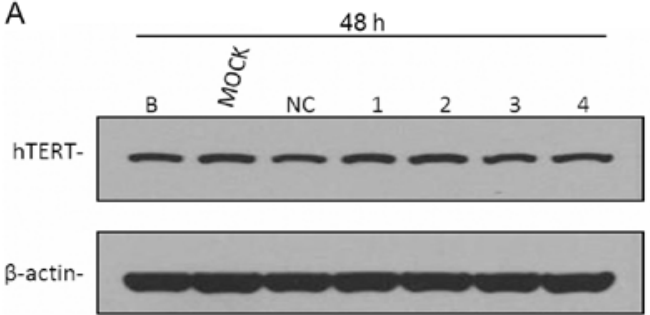

B

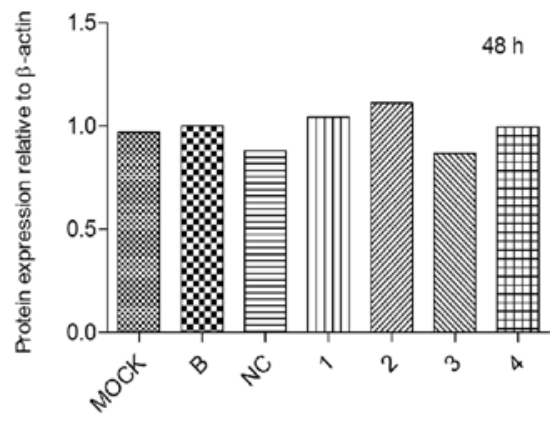

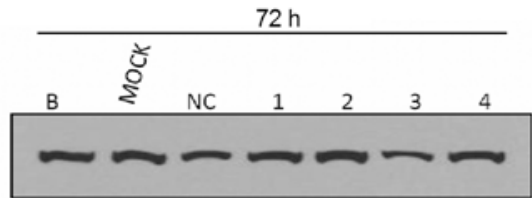
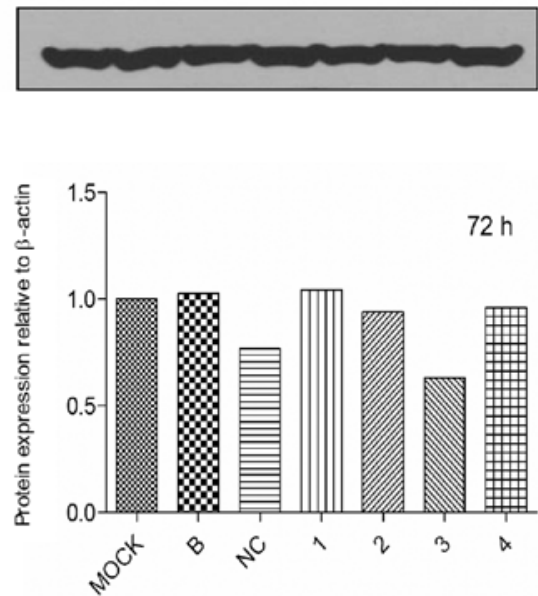

Figure 2. The protein levels were calculated by western blot analyses to determine the effect of treatment of siRNAs at 48 and $72 \mathrm{~h}$.

lated using Graphpad Prime 5.0 in clonogenic assay. All $\mathrm{P}$-values are based on two-sided hypothesis testing, $\mathrm{P}<0.05$ is considered statistically significant.

\section{Results}

Inhibition of hTERT expression. SiHa cells were transfected with siRNAs under optimal conditions. The percentage of cells expressing GFP $6 \mathrm{~h}$ after the transfection was $69.8 \pm 3.0 \%$
(Fig. 1A). hTERT mRNA was not reduced $24 \mathrm{~h}$ after transfection, but markedly reduced $48 \mathrm{~h}$ after transfection. The hTERT expression level was decreased by siRNA\#1-4 to siRNA\#1 $54.33 \pm 6.51 \%$, siRNA\#2 $43.33 \pm 3.51 \%$ siRNA\#3 $63.00 \pm 7.00 \%$ siRNA\#4 56.00 $\pm 9.00 \%$, compared with the control group of mock (Fig. 1B). The protein expression amount in each of the groups was shown in western blot analysis 48 and $72 \mathrm{~h}$ after transfection (Fig. 2A). hTERT protein was reduced by $>40 \%$ in cells after siRNA\#3 transfection (Fig. 2B). Other siRNAs 


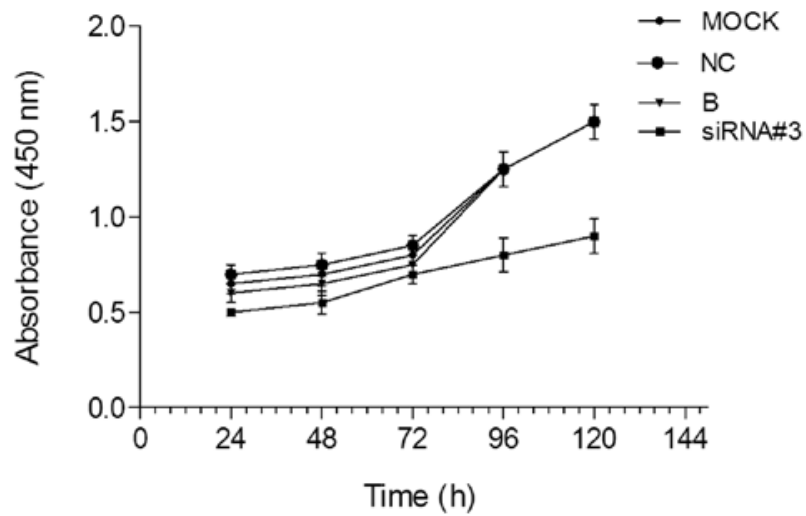

Figure 3. Effect of RNAi-mediated hTERT downregulation on cell proliferation calculated by CCK-8 assay. Cell growth of SiHa with or without transfection was plotted every $24 \mathrm{~h}$. The data of each time-point are average values from three replicates. Graphs show mean absorbance \pm standard deviation; ${ }^{*} \mathrm{P}<0.05$ as compared with the control of NC. also silenced protein expression, but less significantly. In the experiments, no variability was observed in the expression of housekeeping genes (HGAPDH and actin), thus, the RNAi was target-specific. Therefore, we chose siRNA\#3 in the following experiments.

Reduced proliferation in SiHa cells after hTERT knockdown. The effects of transient siRNA\#3 on proliferation of SiHa cells were calculated by CCK-8 assay at 24, 48, 72, 96 and $120 \mathrm{~h}$. As shown in Fig. 3, siRNA\#3 reduced the number of viable SiHa cells significantly, compared with the control of NC. The results showed that downregulation of hTERT resulted in inhibition of SiHa cell proliferation.

The effect of hTERT gene RNAi on cell cycle and apoptosis. We evaluated the cellular effects of hTERT knockdown in SiHa cells. As shown in the cell population in the Q2 quadrant
A
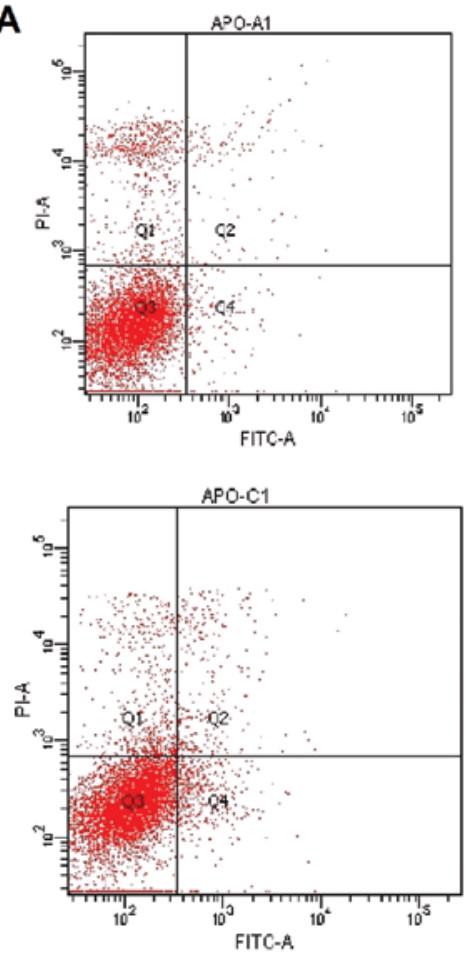
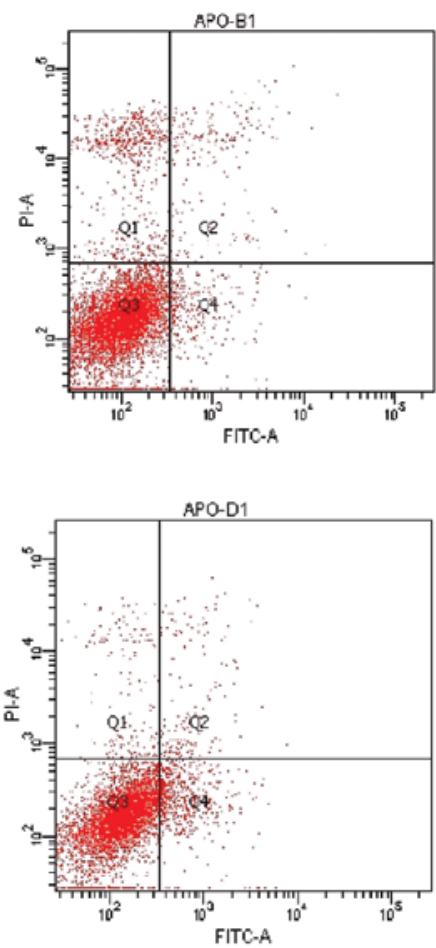

B

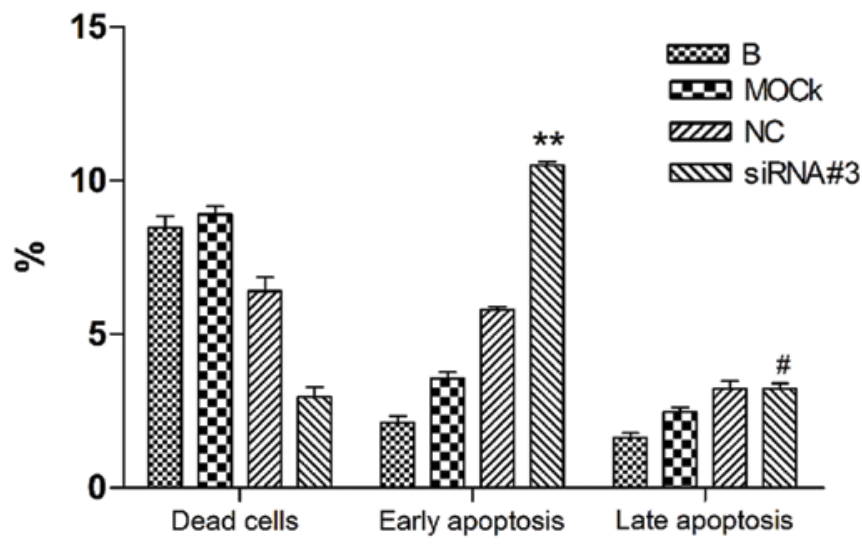

Figure 4. Flow cytometry analysis for apoptotic cells with Annexin V/PI. (A) Representative flow cytometry results of cell apoptosis. A1, Blank. B1, Mock. C1, Negative control. D1, siRNA\#3. Q1, Dead cells. Q2, Late apoptosis. Q3, Early apoptosis. Q4, Viable cells. (B) The percentage of dead cells, early apoptosis and late apoptosis. Data are presented as means $\pm \mathrm{SD}$ of three independent experiments. ${ }^{* *} \mathrm{P}<0.01 ;{ }^{\#} \mathrm{P}>0.05$ compared with the control of NC. 

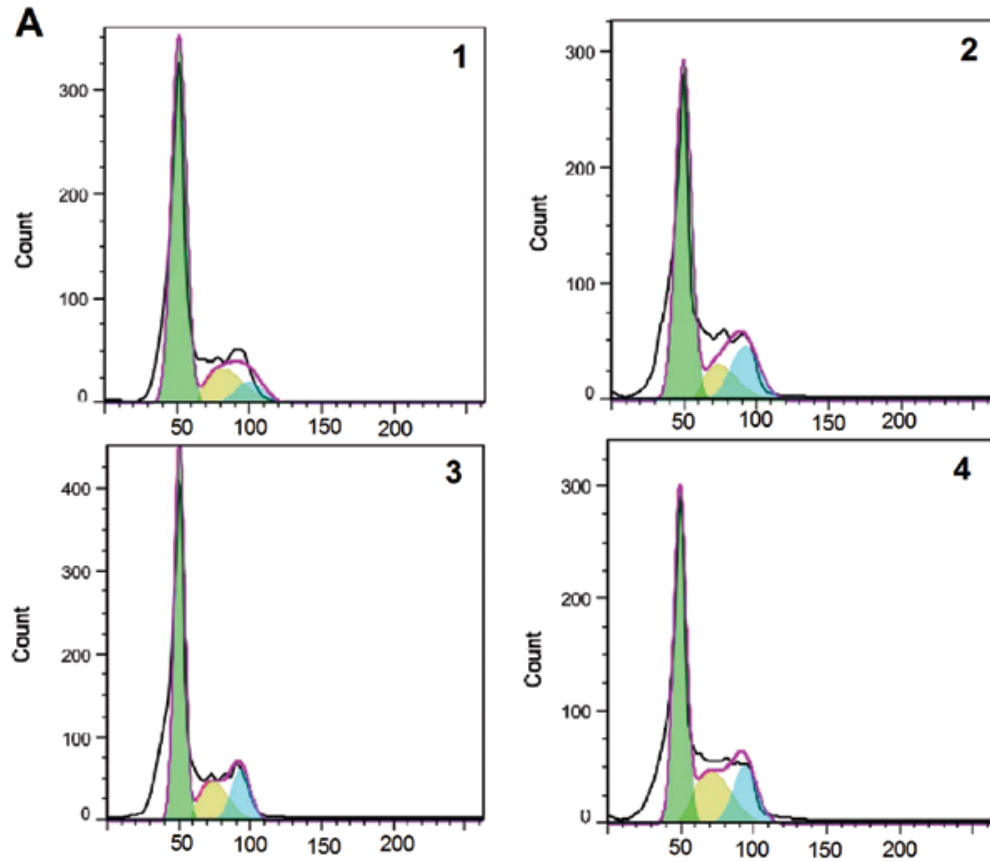

B

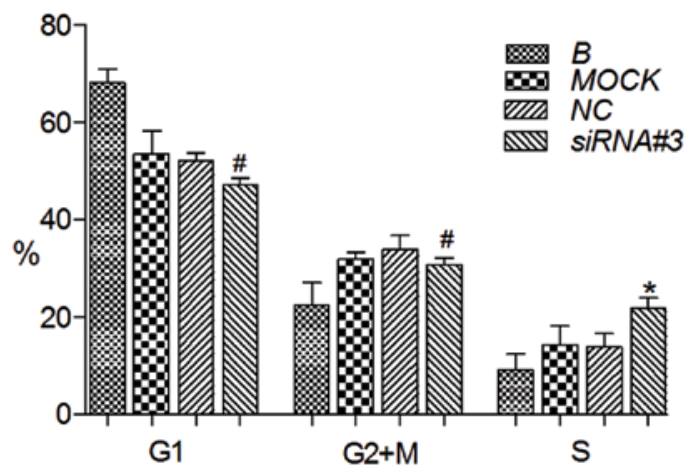

Figure 5. Cell cycle assessment by flow cytometry. (A) Representative results of flow cytometry. 1, Blank (B), 2, siRNA-mate transfection (mock). 3, Negative control (NC). 4, siRNA\#3. (B) The distribution of cells in each cell cycle phase. Data represent the mean \pm standard deviation of three independent experiments. ${ }^{*} \mathrm{P}<0.05 ;{ }^{~} \mathrm{P}>0.05$ compared with the control of $\mathrm{NC}$.

(Fig. 4A), after $48 \mathrm{~h}$ of siRNA\#3 treatment, the early apoptosis rate of $\mathrm{SiHa}$ increased to $10.50 \pm 0.20 \%(\mathrm{P}=0.0006)$, compared with control group of $\mathrm{NC}(5.80 \pm 0.10 \%)$. But the late apoptosis rate of siRNA\#3 $(3.23 \pm 0.31 \%)$ did not increase compared to the control group of $\mathrm{NC}(\mathrm{P}>0.05)$. The rate of dead cells $(2.97 \pm 0.55 \%)$ were slightly decreased compared to NC group (Fig. 4B). The necrotic cells did show slight decrease after siRNA\#3 treatment, thus indicating that the knockdown of hTERT caused early apoptosis instead of necrosis in SiHa cells.

The effect of siRNA\#3 on the cell cycle of SiHa cells was assessed and each test was repeated three times (Fig. 5A). The proportion of cells in $\mathrm{S}$ phase was significantly increased to $21.88 \pm 2.06 \%$ by siRNA\#3 compared to control of $\mathrm{NC}$, $14.01 \pm 2.64 \%(\mathrm{P}<0.05)$. The proportion of cells in $\mathrm{G} 1$ and G2-M was slightly decreased to $47.29 \pm 1.21$ and $30.82 \pm 1.33 \%$, compared to $52.17 \pm 1.63 \%(\mathrm{G} 1), 33.82 \pm 3.09 \%(\mathrm{G} 2+\mathrm{M})$ for NC-treated controls $(\mathrm{P}>0.05)$. The knockdown of hTERT in $\mathrm{SiHa}$ cells led to cell cycle arrest in $\mathrm{S}$ phase (Fig. 5B).

siRNA\#3 enhances radiosensitivity in SiHa cells. The observed survival fractions of two groups were used to form the survival curve with multitarget-single hit model and linear-quadratic model. Then we calculated $\mathrm{D}_{0}, \mathrm{D}_{\mathrm{q}}, \alpha$ and $\beta$ in two groups with Graphpad Prime 5.0. The results (multitarget-single hit model) were $\mathrm{D}_{0}=1.53$ Gy $\mathrm{D}_{\mathrm{q}}=0.77 \mathrm{~Gy}$ for siRNA\#3 and $\mathrm{D}_{0}=2.19 \mathrm{~Gy}$ $\mathrm{D}_{\mathrm{q}}=1.31 \mathrm{~Gy}$ for the control of $\mathrm{B}$ (Fig. 6A). The results of $\alpha$ and $\beta$ calculated with linear-quadratic model were $\alpha=0.45$, $\beta=0.03$ for siRNA\#3 and $\alpha=0.26, \beta=0.02$ for the control of $B$ (Fig. 6B). All results showed SiHa cells treated with siRNA\#3 were more radiosensitive than SiHa cells.

\section{Discussion}

RNA interference (RNAi) could knockdown the mRNAs and protein level of specific genes through post-transcriptional gene silencing mechanism. This technology is of high efficiency, specificity and low toxicity and is used in functional genomic studies and therapeutic gene regulation $(12,13)$. The methods of antisense nucleotides, ribozymes, dominant-negative proteins and surviving promoter-driven siRNA have been developed to inhibit hTERT $(14,17)$. In our study we chose four sites to target hTERT through siRNAs. All siRNAs could 

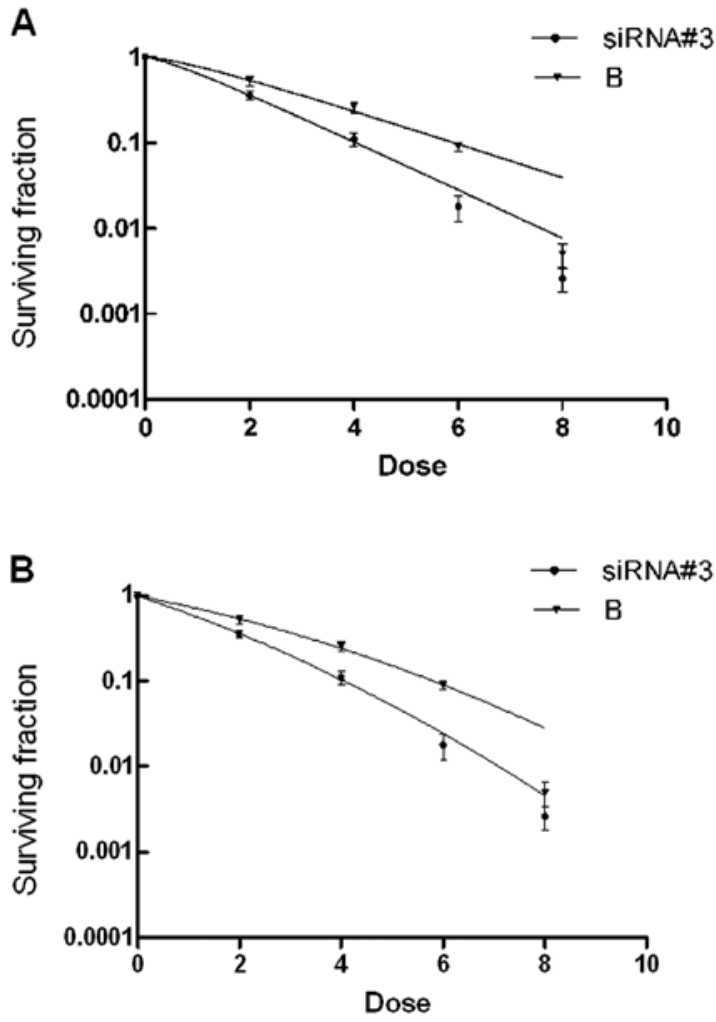

Figure 6. The survival curve. (A) Multitarget-single hit model (B) Linearquadratic model, the curve is represented by the $-\ln (s)=\alpha \mathrm{D}+\beta \mathrm{D}^{2} ; \mathrm{D}$, dose $\alpha$ is proportional to dose, and $\beta$ is proportional to square of the dose.

decrease mRNA level, but only siRNA\#3 silenced hTERT in both mRNA and protein level effectively. It is possible that siRNAs can be potent hTERT inhibitors without immediate cytotoxicity.

Our results show that downregulation of hTERT induces a rapid inhibition in proliferation of SiHa cells. These results are consistent with other reports in different cancer cells (15-18). The cell cycle analysis shows an obvious block in the $\mathrm{S}$ phase. However, contradictory results have been reported. Some reaserch shows that the downregulation of hTERT induces G2 block in breast cancer cells (8), while others induced G1 block (17). The deficient P53 tumor suppressor gene is relative to G1 cell cycle arrest $(19,20)$. Thus, P53 gene may regulate SiHa cells leading to $S$ phase arrest after hTERT downregulation. According to Luo et al, knockdown of hTERT induces inhibition of proliferation of SiHa cells by $\mathrm{S}$ phase arrest (15). Telomerase binding TPP1 at telomere (21) could elongate telomere in rounds of extension (22) during the $\mathrm{S}$ phase of the cell cycle and may also be related with $\mathrm{S}$ phase arrest.

Research has shown there is a close relationship among telomerase, telomere and radiosensitivity $(4,8,17,23-25)$. Ram et al (10) showed that radiation increases telomerase activity specially in cancer cells; furthermore, it is regulated by post-translational mechanism via Ras/phosphatidylinositol 3-kinase/Akt pathway. Findings of Natarajan et al (26) and Natarajan et al (27) indicate that the mechanism of low-let $\gamma$-radiation inducing telomerase activity is $\mathrm{NF}-\kappa \mathrm{B}$ activation. HER-2 positive cells upregulate telomerase activity in irradiated breast cancer cells (28). Also, increased telomerase activity shows greater resistance in skin fibroblast cells (29).
Telomere affects sensitivity to ionizing radiation, the short telomeres have more radiosensitivity than long telomeres and telomere length could act as biomarker of individual chromosome instability upon exposure to radiation (30,31). Drissi et al (32) have reported that kinetics of the DNA damage response is changed in cells with short telomere after ionizing radiation and telomere shortening is related with chromatin structure changes. However, there are also contrary reports on the relationship between telomerase and telomere. Guilleret et al (33) reported that downregulation of telomerase could induce shortening telomere. Conversely, Ji et al (34) have reported that telomeres is unchanged after silencing telomerase. The reason could be that decreased telomerase was not able to change telomere in a short time. We need more information on the cellular pathways in radiation-induced telomerase upregulation, to find targets to enhance radiosensitivity. The clonogenic assay is the gold standard to measure the radiosensitivity of cells. In this study, we used two different models to assess radiosensitivity after silencing hTERT in SiHa cells. All parameters prove that knockdown of hTERT was able to enhance radiosensitivity in SiHa cells.

The results of our study add to accumulating conclusion that telomerase is an important target in regulation of radiosensitivity. Downregulation of telomerase can be an important anticancer therapy in cancer cells. Also, our data suggest that silencing of hTERT leads to rapid growth inhibition, arresting cell cycle in $\mathrm{S}$ phase and early apoptosis. This may offer a future gene-based therapy to alter radioresistance in different cancer cells, and more cancer cells could be destroyed with less severe side effects in radiotherapy through this technology.

\section{Acknowledgements}

This study was supported by a grant from the Natural Science Foundation of Heilongjiang Province China.

\section{References}

1. Collins K and Mitchell JR: Telomerase in the human organism. Oncogene 21: 564-579, 2002.

2. Blackburn EH: Swiching and signaling at the telomere. Cell 106: 661-673, 2001.

3. De Lange T: How telomeres solve the end-protection problem. Science 326: 948-952, 2009.

4. Satra M, Tsougos I, Papanikolaou V, Theodorou K, Kappas C and Tsezou A: Correlation between radiation-induced telomerase activity and human telomerase reverse transcriptase mRNA expression in HeLa cells. Int J Radiat Biol 6: 401-409, 2009.

5. Qi DL, Ohhira T, Fujisaki C, et al: Identification of PITX1 as a TERT suppressor gene located on human chromosome. Mol Cell Biol 31: 1624-1636, 2011.

6. He X, Qiao Q, Ge N, Nan J, Shen S, Wang Z, Yang Y and Bao G: Irradiation-induced telomerase activity and gastric cancer risk: a case-control analysis in a Chinese Han population. BMC Cancer 10: 312-321, 2010.

7. Kyo S, Takakura M, Fujiwara T and Inoue M: Understanding and exploiting hTERT promoter regulation for diagnosis and treatment of human cancers. Cancer Sci 99: 1528-1538, 2008.

8. Gomez-Millan J, Goldblatt EM, Gryaznov SM, Mendonca MS and Herbert BS: Specific telomere dysfunction induced by GRN163L increases radiation sensitivity in breast cancer cells. Int J Radiat Oncol Biol Phys 67: 897-905, 2007.

9. Liu X, Huang H, Wang J, Wang C, Wang M, Zhang B and Pan C: Dendrimers-delivered short hairpin RNA targeting hTERT inhibits oral cancer cell growth in vitro and in vivo. Biochem Pharmacol 82: 17-23, 2011. 
10. Ram R, Uziel O, Eldan O, et al: Ionizing radiation upregulates telomerase activity in cancer cell lines by post-translational mechanism via ras/phosphatidylinositol 3-kinase/akt pathway. Clin Cancer Res 15: 914-923, 2009.

11. Liu X, Jiang L, Wang A, Yu J, Shi F and Zhou X: MicroRNA-138 suppresses invasion and promotes apoptosis in head and neck squamous cell carcinoma cell lines. Cancer Lett 28: 217-222, 2009.

12. Dykxhoorn DM, Palliser D and Lieberman J: The silent treatment: siRNAs as small molecule drugs. Gene Ther 13 : 541-552, 2006.

13. Gazzaniga P, Gradilone A, Giuliani L, et al: Expression and prognostic significance of Livin, Survivin and other apoptosisrelated genes in the progression of superficial bladder cancer. Ann Oncol 14: 85-90, 2003.

14. Cech TR: Beginning to understand the end of the chromosome. Cell 116: 273-279, 2004.

15. Luo Y, Yi Y and Yao Z: Growth arrest in ovarian cancer cells by hTERT inhibition short-hairpin RNA targeting human telomerase reverse transcriptase induces immediate growth inhibition but not necessarily induces apoptosis in ovarian cancer cells. Cancer Invest 27: 960-970, 2009.

16. Zheng JN, Pei DS, Sun FH, et al: Inhibition of renal cancer cell growth by oncolytic adenovirus armed short hairpin RNA targeting hTERT gene. Cancer Biol Ther 8: 1-8, 2009.

17. Wang $\mathrm{R}$, Lin F, Wang $\mathrm{X}$, et al: The therapeutic potential of surviving promoter-driven siRNA on suppressing tumor growth and enhancing radiosensitivity of human cervical carcinoma cells via downregulating hTERT gene expression. Cancer Biol Ther 6: 1295-1301, 2007.

18. Hauguel T and Bunz F: Haploinsufficiency of hTERT leads to telomere dysfunction and radiosensitivity in human cancer cells. Cancer Biol Ther 2: 679-684, 2003.

19. Emastman A: Cell cycle checkpoints and their impact on anticancer therapeutic strategies. J Cell Biochem 91: 223-231, 2004.

20. Tomlinson RL, Ziegler TD, Supakorndej T, et al: Cell cycleregulated trafficking of human telomerase to telomeres. Mol Biol Cell 17: 955-965, 2006.

21. Abreu E, Aritonovska E, Reichenbach P, et al: TIN2-tethered TPP1 recruits human telomerase to telomere in vivo. Mol Cell Biol 30: 2971-2982, 2010.

22. Zhao Y, Abreu E, Kim J, et al: Progressive and distributive extention of human telomeres by telomerase under homeostatic and nonequilibrium conditions. Mol Cell 42: 297-307, 2011.
23. Kurvinen K, Rantanen V, Syrjänen S and Johansson B: Radiationinduced effects on telomerase in gynecological cancer cell lines with different radiosensitivity and repair capacity. Int J Radiat Biol 82: 859-867, 2006.

24. Nedime S, Rikke C, Jesper G, et al: Ectopically hTERT expressing adult human mesenchymal stem cells are less radiosensitive than their telomerase negative counterpart. Exp Cell Res 313: 1056-1067, 2007.

25. Goytisolo FA, Samper E, Martín-Caballero J, et al: Short telomeres result in organismal hypersensitivity to ionizing radiation in mammals. J Exp Med 192: 1625-1636, 2000.

26. Natarajan M, Mohan S, Konopinski R, Aotto R, et al: Induced telomerase activity in primary aortic endothelial cells by low-let $\gamma$-radiation is mediated through NF- $\mathrm{BB}$ activation. Br J Radiol 81: 711-720, 2008

27. Natarajan A, Jamunarani V, Rakhesh M, et al: Curcumin regulates low-linear energy transfer $\gamma$-radiation-induced NF- $\kappa B$ dependent telomerase activity in human neuroblastoma cells. Int J Radiat Oncol Biol Phys 79: 1206-1215, 2011.

28. Papanikolaou V, Iliopoulos D, Dimou I, et al: The involvement of HER2 and p53 status in the regulation of telomerase in irradiated breast cancer cells. Int J Oncol 35: 1141-1149, 2009.

29. Hideaki N: hTERT-immortalized cells useful for analyzing effects of low-dose-rate radiation on human cells. J Radiat Res 49: 9-15, 2008

30. Castella M, Puerto S, Creus A, et al: Telomere length modulateds human radiation sensitivity in vitro. Toxicol Lett 172: 29-36, 2007.

31. Weng D, Cunin MC, Song B, et al: Radiosensitization of mammary carcinoma cells by telomere homolog oligonucleotide pretreatment. Breast Cancer Res 12: R71, 2010.

32. Drissi $\mathrm{R}, \mathrm{Wu}, \mathrm{Hu} \mathrm{Y}$, et al: Telomere shorting alters the kinetics of the DNA damage response after ionizing radiation in human cells. Cancer Prev Res 4: 1973-1981, 2011.

33. Guilleret I and Benhattar J: Demethylation of the human telomerase catalytic subunit (hTERT) gene promoter reduced hTERT expression and telomerase activity and shortened telomeres. Exp Cell Res 289: 326-334, 2003

34. Ji XM, Xie CH, Fang MH, et al: Efficient inhibition of human telomerase activity by antisense oligonucotides sensitizes cancer cells to radiotherapy. Acta Pharmacol Sin 27: 1185-1191, 2006. 